\title{
Procesos constitucionales y procesos arbitrales: ¿agua y aceite?
}

Francisco González de Cossío*

\begin{abstract}
SUMARIO: 1. Introducción. 1.1 Propósito. 1.2 La idea. 1.3. El actual planteamiento es cuestionable. 2. Una mejor visión. 2.1. Hermanos, no detractores. 2.2. Procesos constitucionales. 2.3. Arbitraje. 2.4. Compatibilidad de las instituciones jurídicas. 3. Implementación de la mejor visión. 3.1. ¿El árbitro como parte del sistema de tutela de derechos fundamentales? 3.2.1. Conceptual: epistemología de los mecanismos de solución de controversias. 3.2.2. Pragmática: el costo social del galantismo. 3.5 ¿Control constitucional de los árbitros? 3.5.1. Efecto en la causal de orden público. 4. La visión defendida merece ser seguida. 4.1. Explicación. 4.2. Aclaración. 4.3. Controlemos menos para tutelar más. 5. Conclusión.
\end{abstract}

\section{Introducción}

\subsection{Propósito}

El objeto de esta conferencia es ofrecer una postura sobre un tema que aqueja la región latinoamericana: la relación entre los procesos constitucionales y arbitrales.

Se está librando una batalla intelectual interesante en nuestra región. La batalla es importante. La batalla es disímbola. La batalla es trascendente: de su resultado dependerán muchas cosas. Actualmente la batalla ostenta tanto victorias como derrotas. Éxitos y fracasos. Héroes y heridos -inclusive muertos. Consiste en cómo se conjugan los procesos constitucionales y los procesos arbitrales. ${ }^{1}$

\footnotetext{
* GONZÁLEZ DE COSSÍO ABOGADOS, SC, Ciudad de México (www.gdca.com.mx). Árbitro y postulante. Profesor de arbitraje y competencia. Las apreciaciones (particularmente críticas) sobre esta propuesta son bienvenidas a fgcossio@gdca.com.mx. Este ensayo documenta la conferencia magistral 2014 del CRECIG, Guatemala.

1. Anexo una relación que describe genéricamente el estatus que este tema guarda en diversas jurisdicciones
} 
Este ensayo busca jugar un papel en dicha batalla - y el papel será el de un conciliador. Un avenidor. Un buen componedor. El motivo no sólo obedece a la consideración evidente (dialogar en vez de pelear. Construir en vez de destrui), sino la convicción que ambas instituciones jurídicas tienen un papel importante que jugar, y que no tienen por qué contraponerse. Más aún, el planteamiento actual del tema no es obligado, es destructivo y es lamentable. Lo que es peor, condena a ambos a un resultado que desfavorece a quien debería tener en mente: el gobernado. El tutelado. El "consumidor" de dichos procesos. Para explicar por qué, a continuación describiré brevemente el escenario que estamos viviendo y cómo es producto de un planteamiento cuestionable [1.3.], no sin antes adelantar la idea que pretendo defender [1.2.] Luego procederé a dar los cimientos de la idea [2], cómo implementarla [3], y por qué considero que constituye un mejor resultado que el que invita la discusión actual [4].

\subsection{La idea}

La idea que pretendo defender es que uno puede ser partidario del garantismo, sentirse estimulado por el neo constitucionalismo, entusiasta de la expansión de la tutela constitucional y convencional, tanto nacional como supranacional, y un convencido de la importancia de los derechos fundamentales y los tribunales constitucionales, y aún así defender la noción que no deben interferir en $-\mathrm{y}$ mucho menos obstruir- procesos arbitrales. El motivo: cada uno juega un papel importante y diferente $-\mathrm{i} y$ complementario!

Más aún, dado el estado de eficacia de los procesos constitucionales en la región, no adoptar la postura defendida tiene por efecto [1] entorpecer los procesos en las relaciones de coordinación (incluyendo el arbitraje), [2] distraer los procesos constitucionales al incluir dentro de su ámbito de atención áreas que los necesitan menos, y [3] diluir los recursos disponibles para procesos constitucionales, al ser empleados en áreas donde se requieren menos, distrayéndolos de las áreas donde se necesitan más.

Latinoamericanas. El objetivo no es dar una opinión exhaustiva, sino fundamentar y permear el punto al que aludo en el texto: su caleidoscópico statu quo en la región. 


\subsection{El actual planteamiento es cuestionable}

En su mayoría, el planteamiento actual que observo despierta, en su aspecto analítico, lo que en la lógica llamamos un "falso dilema"2. Y en su aspecto retórico, lo que los psicólogos llaman un diálogo de sordos.

La mayoría de los intelectuales que han adoptado posturas sobre este tema son catalogables en uno de dos bandos: los constitucionalistas y los arbitralistas. Y las posturas que adoptan tienden a dar preferencia a la disciplina sobre la cual se especializan, buscando supeditar la otra.

Postulo que ello es tan cuestionable como lamentable.

Es cuestionable pues el análisis de supeditación —quién o cuál es más importante- es un ejercicio intelectualmente arduo y poco meritorio. Algo así como discutir sobre qué es más importante, un martillo o un desarmador.

Respetuosamente, expender energía para defender uno u otro es desperdicio. Dirigir energía a un fin banal. El análisis de supeditación no deja nada. Usemos nuestras (escasas y valiosas) armas intelectuales para fines que los justifican $-\mathrm{y}$ de preferencia fines constructivos.

Es lamentable pues sesga análisis y arroja resultados indeseables. Si se prefiere al arbitraje, los paladines del constitucionalismo detractarán y se preocuparán - y con razón. Si se prefiere el constitucionalismo, los arbitralistas se inquietarán por su impacto en la eficacia del arbitraje.

¿Por qué no mejor reconocer que ambos juegan un papel importante y distinto. En sus respectivas esferas de aplicabilidad, cada instrumento tiene un propósito que guarda un común denominador y una diferencia. La diferencia es el derecho que aplican. El común denominador es que ambos buscan (eventualmente) lo mismo: respeto del Derecho. Ambos son aliados del Estado de Derecho. Ambos son instrumentos que, en sus respectivas áreas de aplicación, tienen un valor que dar, una misión que cumplir. Por ende, verlos como enemigos es artificial. Es ver gigantes donde hay molinos. $\mathrm{Y}$ al margen del yerro conceptual, existe un resultado pragmático lamentable: da municiones para el uso fariseo (abusivo y obstructivo) del Derecho.

2. Véase, Garantismo y ARbitraje: un FAlso Dilema, XIII Congreso Nacional de Abogados de la Barra Mexicana, Colegio de Abogados, A.C. (San Luis Potosí, mayo 2012), y su post scritum (ambos visibles en www.gdca.com.mx). 


\section{Una mejor visión}

\subsection{Hermanos, no detractores}

En vez de dirigir nuestras armas los unos a los otros, los constitucionalistas y los arbitralistas deberíamos entender que somos aliados en un mismo fin. En vez de enfrentar, deberíamos colaborar. En lugar de guerras intelectuales fratricidas, deberíamos reconocer que compartimos un mismo ideal: el respeto por el Derecho. La procuración de un Estado de Derecho. El que sea una rama diversa del Derecho no cambia que es parte del Derecho.

Los procesos constitucionales tienen por objeto defender derechos fundamentales. Los procesos arbitrales tienen por objeto defender derechos de otra índole, contractuales o ex lege. Pero derechos al final del día.

Cuando olvidamos lo anterior, distraemos. Dirigimos nuestras armas intelectuales entre nosotros, en vez de dirigirlas hacia el verdadero enemigo. Al hacerlo, desperdiciamos el filo de nuestras navajas en batallas entre pares. Y para cuando debemos enfrentar al verdadero enemigo, las navajas están desafiladas.

Si el lector está dispuesto a aceptar esta relectura, paso a explicar cómo lograrla.

\subsection{Procesos Constitucionales}

La idea de la Constitución es poderosa y estimulante. Tanto en su aspecto sustantivo (la existencia de un puñado de principios universalmente aceptados como importantes - los "derechos fundamentales") como adjetivo (la Garantía Jurisdiccional de la Constitución). Sea que se trate del modelo austriaco, concentrado, o del modelo americano, difuso, la posibilidad de sujetar a control constitucional el ejercicio del poder es una de las grandes victorias de la ciencia del Derecho. El objetivo: que la Constitución sea un instrumento viviente-no sólo vigente. 


\subsection{Arbitraje}

El arbitraje, en su esencia, descansa en la libertad ${ }^{3}$, tanto contractual como procesal. La posibilidad de escoger una forma de encausar y resolver problemas diversa a la ofrecida por el Estado. Además, dadas sus características, el arbitraje se funda también en la certeza y seguridad jurídica.

La idea es sencilla, pero poderosa. El Estado ofrece una infraestructura para resolver problemas - la justicia estatal. Dicha opción, como toda opción, tiene características: ventajas y desventajas. Por definición ello la hace apta, idónea, para cierto tipo de problemas. Pero también por definición no es adecuada para otros ${ }^{4}$. Es ello lo que logra el arbitraje: la posibilidad de hacer uso de la libertad contractual para moldear una solución a las necesidades del problema. Inter alia permite elegir el intelecto de quien actuará como juzgador (el árbitro) y confeccionar un proceso como traje a la medida para lo que necesita 5 .

\subsection{Compatibilidad de las instituciones jurídicas}

Entendida la razón de ser de cada institución jurídica, ¿es incompatible el ideal de control de poder con el ideal de libertad?

Postulo que la respuesta es negativa. Ambos ideales no solo no se contradicen, se refuerzan. La libertad de encausar y resolver una disputa en forma diversa a la generalmente disponible es perfectamente compatible con la [estimulante] idea que el poder debe ser ejercido conforme a cierto cauce. Que hay principios elementales, fundamentales, que nos aplican a todos, y que permean en todos los sistemas, por lo que irradian aplicación a todos. Y dichos principios son, como explica elocuentemente DwORKIN, "cartas de triunfo frente a las mayorías" 6 . "Derechos que nos corresponden universalmente a todos en cuanto dotados del estatus de personas" adoptando la definición de Luigi FerRajoli" "Intereses fundamentales para

3. Para una lectura fresca y estimulante sobre esta noción, ver J. PAULSSON, THE IDEA OF ARBITRATION, Oxford University Press, 2013.

4. Al respecto, véase el capítulo II de Arbitraje, Ed. Porrúa, México, DF, 4a edición, 2014.

5. Desarrollo esta idea, como punto de partida de toda mi obra, en Arbitraje, Ed. Porrúa, 4a edición, 2014.

6. R. DWORKIN, TAKING Rights SERIOUSLY, Harvard University Press, USA, 1978.

7. Derecho y Garantías. La Ley Del Más DÉBil, Editorial Trotta, Madrid, 2010, p. 37. 
el florecimiento del humano", como los concibe John Finnis ${ }^{8}$. O el "Conjunto de prerrogativas inherentes a la naturaleza de la persona cuya realización efectiva resulta indispensable para el desarrollo integral del individuo" como explica la Ministro de la Suprema Corte de Justicia de México, la doctora Margarita Luna Ramos ${ }^{9}$.

Lo anterior debe servir de punto de partida analítico, pues es la esencia de ambas instituciones. No hacerlo arroja un resultado que dista de estar en sintonía con el leitmotif de cada institución jurídica. Dicha esencia debe siempre tenerse presente pues, como se ha explicado antes, una concepción diversa tiene (ha tenido) por efecto que, lo que en verdad son hermanos en ideales, se tornen en enemigos conceptuales.

Postulo que dicha compatibilidad existe inclusive ante la expresión más estimulada de la idea de la Constitución. Después de todo, la libertad (implícita en la idea del arbitraje) es uno de los derechos más caros de todos los instrumentos constitucionales.

\section{Implementación de la mejor visión}

Aceptado el punto de partida, la pregunta obligada es "cómo". ¿Cómo lograr la postura por la que abogo?

Propondré una senda a partir de tres puntos de intersección de ambas disciplinas que propician dudas que la implementación de la visión tendría que resolver:

a) ¿Cuál es el papel del árbitro en el sistema de tutela de derechos fundamentales?

b) ¿Es necesario control constitucional de la actividad de los árbitros?

c) ¿Qué efecto tiene mi visión en la causal de orden público?

8. J. Finnis, Human Rights and Common Good, Collected Essays: Volume III, Oxford University Press, p. 28.

9. M. Luna Ramos, Las Personas Morales itienen Derechos humanos?, El Universal, 6 de mayo de 2014, sección de Opinión, p. A18. 
A continuación propongo respuestas que someto a la consideración de este público.

\section{1. ¿El árbitro como parte del sistema de tutela de derechos fundamen- tales? 10}

Vista desde la perspectiva constitucionalista, la idea que aquí planteo exige responder la pregunta ¿qué papel deben jugar los tribunales arbitrales en el sistema nacional e internacional de tutela de derechos fundamentales?' Si la obligación de hacer control difuso de constitucionalidad y convencionalidad aplica a los tribunales arbitrales. Si el "bloque de constitucionalidad" y "bloque de convencionalidad" es parte del "Derecho" que el árbitro privado debe aplicar para resolver el caso concreto ${ }^{11}$. Si el árbitro debe entenderse como "juez interamericano" humanitario, y por ende aplicar el corpus iuris trasnacional ${ }^{12}$ que está en vías de tejerse - uno de los desarrollos jurídicos más estimulantes de los últimos tiempos.

Postulo ante este foro de expertos que la respuesta debe ser negativa. El motivo es tanto conceptual como pragmático. Me explico.

\subsubsection{Conceptual: epistemología de los mecanismos de solución de controversias}

Los mecanismos alternativos de solución de controversias, incluyendo el arbitraje, son una opción. Una alternativa a la regla que todos tenemos el derecho fundamental a obtener tutela judicial del Estado. Dicho

10. La forma en que he planteado la pregunta es cuestionable, lo admito. Si lo he hecho así obedece a que deseo adoptar el ángulo analítico más difícil de defender, pero más estimulante, y desde la perspectiva de la postura constitucionalista.

11. Ello incluiría el "diálogo jurisprudencial" regional y nacional al que alude E. FERrER MAC-GREGOR, (PANorámica del Derecho Procesal Constitucional y Convencional, UNAM, Ed. Marcial Pons, México, 2014 p. 681). Incluiría el derecho escrito y jurisprudencial del sistema jurídico involucrado, el corpus iuris humanitario (tanto interamericano como comparado - europeo y africano - cuando orientativo).

12. Nótese el término, que no recibe eco en la literatura especializada sobre el tema. Mientras que algunos hablan de un "Derecho Público Interamericano" (v.gr., FERRER MAC-GrEgor, ob. cit., p. 681), utilizo el término "trasnacional" para hacer aplicable las ideas de P. C. Jessup (TRASNATIONAL LAW, Yale University Press, New Haven, 1956) consistentes en la universalidad de los problemas que aquejan a la humanidad, y cómo el derecho que cada sistema destila es uno, trasnacional, que corta transversalmente a todos los sistemas jurídicos. La idea me ha estimulado desde hace mucho en esencia por dos motivos. Primero, su visión macro, mundialista, de la humanidad, que resta importancia a las (artificiales) fronteras y evita caer en nacionalismos - lo cual tanto daño nos ha hecho. Segundo, porque invita un uso diestro y pragmático 
derecho es una opción. Y dicha opción tiene características que lo hacen idóneo para ciertos casos, e inútil para otros. Es decir, el proceso judicial, como todo instrumento, es por definición ideal para cierto tipo de problemas, y también por definición no es ideal para otros ${ }^{13}$.

Los problemas deben ser analizados como patologías. Deben palparse a efecto de discernir qué medicina necesitan: litigio, arbitraje, mediación, conciliación, peritaje o dispute boards. Se trata de medicinas distintas para males distintos. El motivo: cada figura aporta un valor diverso. Y dentro de dicho valor no está el de ser parte del sistema interamericano de tutela de derechos fundamentales. Visto desde la (aguda) perspectiva de Salvatore Natoli y Luigi FerRajoli ${ }^{14}$, el "dolor" que busca colmar es diverso. No se trata de un dolor infligido, sino un dolor sufrido ${ }^{15}$.

Esto no quiere decir que los árbitros violen derechos fundamentales. Quiere decir que no son el instrumento para garantizarlo. Este punto es sutil, pero importante. Un derecho puede ser tutelado desde ángulos distintos ${ }^{6}$. Pero ello no quiere decir que todos los ángulos requieran los mismos recursos procesales.

La postura anterior se complica en los sistemas jurídicos donde existe control difuso. De hecho, tengo que admitir que la exposición tiene un ligero sesgo:

de la disciplina del Derecho Comparado. En mi opinión, la utilidad mayor del Derecho Comparado es que permite aprender de la experiencia ajena, evitando repetir errores. Permitiendo confeccionar mejores soluciones (regímenes jurídicos) cuando se capitaliza en la sabiduría derivada de la experiencia ajena.

13. Esta apreciación es frecuentemente pasada por alto, particularmente por los detractores del arbitraje. Para estos personajes, el arbitraje no sirve para nada. Y si se escuchan sus motivos, el pensador cauteloso se percatará que son técnicamente inadecuados, con frecuencia consisten en exposiciones incompletas (muchas veces, desinformadas) de temas o casos de arbitraje, y muchas una (a veces iracunda) predisposición en contra. Considero que ello es lamentable. Los mecanismos alternativos de solución de controversias, incluyendo el arbitraje, son herramientas útiles para ciertos casos, e inútiles para otros. Ello, respetuosamente, es la exposición objetiva y correcta del punto. Y la apreciación también se extiende al litigio: es ideal para ciertos casos, y subóptimo para otros. Cuando un abogado se ciega a esto, lo único que logra es cerrarse puertas - y a sus clientes. Querrá decir que hay un universo de casos que está mal aconsejando, pues eran mejor encausados por vías distintas al litigio.

14. Derecho y Dolor. la Crisis del Paradigma Constitucional, en El Canon NeoconstiTUCIONAL, Universidad del Externado de Colombia, Serie Intermedia de Teoría Jurídica y Filosofía del Derecho número 8, Bogotá, Colombia, 2010, p. 145.

15. FERRAJOLi hace eco de la justificación del Derecho que S. NAtoli propone: como solución a dos tipos de dolores: el "sufrido" y el "infligido". El primero es natural, el segundo causado por el hombre.

16. Por ejemplo, la vida, que puede ser tutelada desde la perspectiva de derecho constitucional, convencional (artículos 4 y 5 del Pacto de San José) y penal (sancionando el homicidio: artículo 302 del Código Federal Penal). La propiedad: artículo 27 de la Constitución, artículo 21 del la Convención Americana de Derechos Humanos y artículo 367 del Código Federal Penal (que sanciona el robo). 
proviene de un abogado educado en el modelo concentrado de control constitucional ${ }^{17}$. Con mis antecedentes, la exposición anterior tiene un ángulo diverso al que probablemente adoptaría un practicante o juzgador entrenado y acostumbrado al control difuso ${ }^{18}$. ¿Quiere lo anterior decir que la idea aquí presentada es inaplicable a los sistemas con control difuso? Propongo que no. En dichos casos, el árbitro realizaría una interpretación conforme ${ }^{19}$, que no estaría sujeta a los mecanismos, recursos de alzada, del control constitucional. El árbitro aplicaría la jurisprudencia interamericana y local constitucional y convencional como parte del "Derecho" aplicable para resolver la controversia. Pero el laudo no sería revisable en cuanto a ello, pues dicho ejercicio estaría revestido de 'finalidad', como una cuestión de derecho sustantivo ${ }^{20}$.

17. Hasta 2011 México siguió un sistema de control constitucional concentrado. A partir de entonces es mixto: coexisten el control concentrado (por jueces constitucionales) y difuso (que aplica a todas las autoridades en el ámbito de sus competencias).

18. Por ejemplo, proveniente de República Dominicana o Perú. Estoy en deuda con el Magistrado E. ALARCóN, la doctora M. FERnÁnDEZ y J. R. FERIS por sus amables (pero arduos) comentarios sobre el tema desde la perspectiva de República Dominicana. A su vez, con A. BULLARD por sus apreciaciones desde la perspectiva peruana.

19. No podrían analizar la validez de leyes con efectos erga omnes, lo cual corresponde a tribunales constitucionales. Lo más que podrían hacer es una interpretación conforme, incluyendo (en casos extremos) la no aplicación en el caso concreto de una norma considerada inconstitucional.

20. En este contexto se torna relevante la postura vertida por el Dr. L. Pereznieto CAstro, en El Control Difuso por Tribunales Arbitrales (La Barra, Revista de la Barra Mexicana, Colegio de Abogados, No. 92, Julio-Octubre, 2014, p. 10). Dicho jurista hacer ver que el árbitro puede tener quehacer control difuso. Su análisis - que entiendo como el comienzo, no fin, de una discusión- pone el dedo en la llaga del gran tema a resolver. Del mismo tengo similitudes, diferencias y puntos que someto a su respetada consideración. Similitudes: Comparto su apreciación que el ejercicio puede ser resultado del Derecho aplicable (\$4(b), p. 13). Al hacerlo, invito a quienes difieran a que consideren que esto es parte del nuevo paradigma que se suscita por la adopción por México del modelo mixto de control de constitucionalidad y convencionalidad. No podemos cerrarnos los ojos al tema. El Dr. PEREZnIETo hace bien en iniciar esta discusión. Sin embargo, al día de hoy, dicha postura tiene que tomar en cuenta que el control difuso en México es una obligación impuesta a autoridades (Art. 1, para 3, de la Constitución). Siendo que el árbitro ha sido consistentemente entendido como que no actualiza la hipótesis de 'autoridad' (ni para efectos de amparo, ni para otro fin), ¿cómo se justificaría el ejercicio?

Diferencias: el árbitro no es "auxiliar de la justicia"; no forma parte del aparato estatal de forma alguna - incluyendo la (amorfa) noción de auxiliar de la justicia que en el pasado ha servido para remediar otros problemas en la aplicación del juicio de amparo.

Proposiciones: (1) la apreciación que el control difuso del árbitro es más amplio de lo que puede ejercer un juez local (id., p. 14) es matizable en que no admite generalización. Por un lado, el árbitro que aplica Derecho del país $X$ cuyos jueces constitucionales han, por ejemplo, declarado la invalidez de una norma con efectos erga omnes, tendría que acatar dicha decisión, producto del sistema que conforma el "Derecho" que aplica. (Pero propondría que no es revisable en el contexto del juicio de nulidad o no ejecución. Para una postura contraria, ver el caso peruano desde el caso María Julia, que permite revisión del laudo para cerciorar que no se viola un precedente del Tribunal Constitucional de observancia obligatoria.) Aunado al hecho que el árbitro no puede declarar la invalidez de normas inconstitucionales o inconvencionales, ello militaría a favor de considerar que la apreciación no es correcta. Por otro, el árbitro no está maniatado ante las determinaciones sobre inconstitucionalidad o inconvencionalidad de los juzgadores locales. Esta es la esencia de la (profunda, estimulante y frecuentemente malentendida) postura por la que aboga J. PAULSSON en su debate con P. MAYER (J. PAUlsson, Unlawful Laws and the Authority of International Tribunals, 23 ICSID Review 215 (2008); P. MAYER, L'arbitre inernational et la hiérarchie des normes, Revue de l'arbitrage, 2011 p. 361 y J. PAULSSON, The 
Auguro que esta postura hará hervir la sangre de algunos: ¿O sea que los árbitros privados aplicarán derecho constitucional sin estar sujetos a los mecanismos procesales que se cercioran que el mismo está correctamente aplicado -mismos que aplican a los jueces mismos?21 Respuesta: "sí". Motivo: porque el laudo es final. Porque ese fue el deseo de las partes al optar por un mecanismo alternativo de solución de controversias. ¿Alternativo a qué? - Al sistema judicial. Cualquier postura distinta sería contraria a la voluntad de las partes. Si una parte se somete al arbitraje, que es uni-instancial, es porque desea que todo sea resuelto en una sola instancia -incluyendo el Derecho público aplicable.

\subsubsection{Pragmática: el costo social del garantismo ${ }^{22}$}

Con todo el respeto que tengo a los teóricos y practicantes de los procesos constitucionales, existe un problema serio que nos aqueja, y que no sólo no se ha remediado, sino que todo parece indicar que distamos de arrojar síntomas de mejoría en el futuro no sólo inmediato, sino mediato.

Como regla, los procesos constitucionales de nuestra región tienen un margen alto de ineficacia. Me he abocado a estudiar los procesos constitucionales en la región. Sin ostentarme como experto, detecto cinco constantes se relacionan con nuestro tema y que han tenido por efecto mermar seriamente su eficacia:

Idea of Arbitation, p. 231 et seq) y que el Dr. PEREZnIETO permea (id., pp. 13-14). Lo profundo y estimulante (además de precioso, para mi gusto) de la (controversial, pero inadvertida para muchos) postura de es que da margen de maniobra al árbitro internacional para evitar ser forzado a ser parte del Derecho como instrumento de opresión, lo cual ex hypothesi significa que algo anda mal con el funcionar del Poder Judicial local - algo que lamentablemente sigue pasando en algunas equinas del mundo.

(2) El que el árbitro pueda estar obligado a efectuar control difuso no depende de la sede sino del Derecho sustantivo aplicable, incluyendo si el Derecho en cuestión lo exige; mas no por la sede - que no es más que el vínculo que ata un tribunal arbitral a un derecho arbitral local. Dicho de otra manera, un árbitro con sede en un país donde no exista control difuso puede no obstante ello tener que efectuar control difuso cuando el Derecho aplicable sea de otro país que así lo exige. Y viceversa. La sede no es dispositiva de dicha cuestión. (Me interesará conocer la respetada opinión del Dr. PEREZNIETO sobre las anteriores reflexiones.)

21. Nótese que planteo la pregunta de la forma más provocadora posible. El motivo obedece al principio de argumentación que exige vencer un argumento en su expresión más robusta, no más débil. Una expresión menos escandalosa podría ser “¿El principio de finalidad del laudo se extiende también a las cuestiones de derecho constitucional o convencional, cuando aplicable?".

De hecho, existe una corriente de opinión que considera que existe un 'derecho humano arbitral': el derecho fundamental a contar con procedimientos arbitrales libres de intervención judicial. (Véase, el DERECHO HUmano Arbitral, Boletín del Centro de Arbitraje de la Industria del a Construcción (mayo 2013), visible en www.caic.org.mx). Para conocer la respue sta judicial a dicha teoría, véase El Derecho Humano Arbitral, (XIV Congreso Nacional de Abogados, 7 y 8 de Noviembre de 2014, visible en www.gdca.com.mx).

22. Para abundar sobre esto, ver El Costo Social Del GARAntismo, XIV Congreso Nacional de Abogados, Barra Mexicana, Colegio de Abogados, Puebla, 7 y 8 de noviembre de 2014. 
i) Dilución: como dice el viajo adagio "el que mucho abarca, poco aprieta". Cuando una misma herramienta se utiliza para todo tipo de fines, el resultado es que se mal emplea. Se diluye. Ello ha acontecido con los procesos constitucionales. Al hacerlos aplicables a áreas distintas a su núcleo duro, el resultado es que se merma la energía disponible. Se expenden recursos en espacios que no los necesitaban tanto - inclusive que no los justifican. Y siendo que los recursos son finitos ${ }^{23}$, el resultado natural es que se distraen de donde se deberían enfocar. De las áreas en las que se deberían concentrar.

ii) Procesalitis: con frecuencia el régimen aplicable a los procesos constitucionales es formal y obeso. Se observa una enorme sobre-regulación de todos los aspectos del proceso. Y entre más forma y requisitos, más probabilidad de error. Aunado al fetish por la formalidad, ello tiene por efecto dar múltiples ocasiones para obstruir

iii) Exceso de recursos: la mayoría de los sistemas de derecho procesal constitucional suelen contar con una cantidad enorme de recursos intraprocesales - además de los recursos aplicables una vez concluido el proceso. Ello impacta seriamente su eficacia, pues muchos de los recursos suelen suspender el proceso mientras se admiten o deciden. Ello tiene un doble efecto. Primero, logra el objetivo de una parte que desea obstruir. Segundo, le complica la labor al juez. El juzgador que tiene que visitar y adentrarse a un expediente muchas veces es mucho menos eficaz que el juzgador que lo hace una sola vez. Y si ello se multiplica por el número de casos que cada juzgador tiene, el resultado natural es sobre-saturación ${ }^{24}$.

Aunado a la (enorme) sobre-regulación (comentada en el punto anterior) ello resulta en [1] suspensiones de procesos para atender recursos intraprocesales; [2] repeticiones (a veces múltiples) de los procesos en todo

23. Y los recursos siempre son finitos, especialmente los recursos públicos; y especialmente es países en vías de desarrollo.

24. Es decir, no sólo saturación, sino saturación que no se justifica. Que es innecesaria. 
o en parte; y [3] tácticas dilatorias diversas que capitalizan dichas suspensiones y repeticiones, para procurar retrasar o descarrilar procesos ${ }^{25}$. Y con mucha frecuencia por aspectos que no lo justifican ${ }^{26}$.

iv) Tolerancia del abuso de proceso: por motivos que no acabo de entender, los latinoamericanos tendemos a tolerar el abuso de proceso. La parte que obstruye procesos es solapada. Fuera de comentarios académicos y en foros, los juzgadores latinoamericanos (incluyendo árbitros) tienden a no hacer nada ante abuso procesal $^{27}$.

v) Costas: un caso particular de lo anterior que merece mención independiente es la distribución de costas. Por lo general, los fallos (sentencias o laudos) hacen poco análisis sobre la distribución de costas, y con frecuencia los montos pueden ser importantes. Como resultado, no sólo toleran abuso de proceso, ¡sino que lo incentivan! El motivo: cuando el costo de un proceso no es atribuido a quien lo genera, se impone un costo sobre la parte que litiga con decencia que es generado por la parte que propicia los costos. Ello incentiva litigio 'sucio' pues hace que la estrategia dominante ante el mismo sea incurrir en el mismo.

Aunque diferentes sistemas jurídicos locales actualizan en forma diversa lo anterior, casi todos adolecen de alguna manera u otra de todos los síntomas indicados. Y la gran constante es que dichos procesos:

a) Están disponibles para pocos: Sirven en su mayoría a quienes tienen la posibilidad económica de contar con un abogado especializado (y oneroso). Como resultado, para una buena parte de la población de nuestra región, los derechos fundamentales no son

25. Un efecto secundario pero importante de esto es que los procesos pierden su 'tempo'. La atención eficiente de un expediente requiere que la atención se concentre para procurar resolverlo en una sola ocasión. No lograrlo resulta en desperdicio de energía, atención y tiempo. Y la calidad de los fallos con frecuencia se ve mermada por ello.

26. La regla consistente en que una violación formal de minimis no justifica cuestionar, anular o repetir todo un proceso es de excepcional aplicación. Se postula que para que una violación procesal justifique la nulidad del proceso o su consecución de novo, debe lesionarse seriamente un derecho procesal. Las violaciones de minimis deben ser insuficientes.

27. Ante mi (reiterada) crítica sobre esto, se me indica que puede ser difícil discernir entre uso y abuso de un derecho procesal. Difiero. Quien conoce un expediente sabe si ha habido abuso procesal. 
más que poesía que escuchan en los medios y en las cátedras de grandes pensadores, pero que no tienen efectos palpables en su vida cotidiana.

La importancia de esto no debe ser subestimada. Algunos han hablado de "Estados fallidos" en nuestra región. Otros se indignan. Este es uno de los fracasos más serios de los sistemas judiciales de nuestra región. Merece nuestra atención. Aceptémoslo.

b) Son ampliamente utilizados para estorbar.

Para obstruir sea el ejercicio legítimo de derechos o el ejercicio de las facultades regulatorias de autoridades. Ante lo anterior, someto a la consideración de este público que debemos:

i) Simplificar: Hacer menos compleja la hebra procesal de la disciplina a efecto de hacerla accesible a una mayor parte de la población;

ii) Eficientar: Hacerla más eficaz, diseñando procesos más esbeltos y menos proclives a accidentes procesales ${ }^{28} ; \mathrm{y}$

iii) Enfocar: El juicio de amparo debe ser un rayo láser, no una escopeta. Circunscribir su aplicación a efecto de evitar dilución.

Todo lo anterior se relaciona con nuestro tema en que, mientras las medidas correctivas son tomadas, o para los casos en que se desea cursar de manera distinta la solución de un problema, existe el arbitraje y los MASC. Sin embargo, si le hacemos aplicable los procesos constitucionales, querrá decir que no hay opción. Que quien desee encausar en forma distinta la solución de sus problemas, siempre acabará en tribunales.

28. Los juzgadores con frecuencia se quejan del cúmulo de casos que enfrentan. La crítica es atendible de muchas maneras, una de las cuales es resolver cada caso más rápido (para lo cual, aplica lo indicado sobre menos recursos intraprocesales) y atribuir costos a quien los genera, lo cual desincentiva su abuso. 


\section{2. ¿Control constitucional de los árbitros?}

¿Es necesario sujetar a control constitucional a los árbitros? La pregunta es profunda. Para resolverla lo primero que hay que discernir es que no es lo mismo control difuso de constitucionalidad y convencionalidad por el árbitro que control de constitucionalidad y convencionalidad de los actos del árbitro. La primera cuestión quedó abordada en la sección anterior. La segunda es objeto de esta.

No faltará quien conteste que "si" aduciendo que toda conducta debe ser acorde a la Constitución. La aseveración me merece dos apreciaciones. Primero, ello no es evidente. La raison d'être de una Constitución es limitar poder público ${ }^{29}$. En la medida en que los árbitros no cuentan con poder, la preocupación que justifica control constitucional no está presente ${ }^{30}$.

Segundo, aunque uno estuviera de acuerdo en que toda la actividad humana esté acorde a un texto constitucional, ello no quiere decir que la misma tenga que estar sujeta a control constitucional a través de los mecanismos del derecho procesal constitucional. La constitución contempla y permite el derecho civil y mercantil. Y dichas disciplinas tienen su propio régimen sustantivo y adjetivo. Éste último no tiene que coincidir con el derecho procesal constitucional por el simple motivo que es una disciplina con un régimen adjetivo especializado. Ello obedece a un motivo. $\mathrm{Y}$ ello cumple un motivo: la lex specialis procesal obedece a que la disciplina sustantiva a la que aplica tiene 'algo' que exige tratamiento procesal especializado. Sumarle una capa de procesos constitucionales no es obligado, y puede tener $-\mathrm{y}$ ha tenido, cuando ha ocurrido- el efecto de aletargar ${ }^{31}$.

29. Me refiero al aspecto dogmático de las constituciones. Existe además el aspecto orgánico que versa sobre algo diverso: la organización del Estado.

30. Hay quien aduce que los árbitros tienen mucho poder. Contestaría que no es 'poder' en el sentido tutelado por los procesos constitucionales. Cuando dos partes en disputa le piden a un particular que actúe como árbitro y diga a quién asiste el Derecho y la razón, eso no es 'poder' en el sentido tutelado por el derecho de amparo. Es un acto de confianza.

31. Uno de los grandes aciertos del derecho procesal constitucional mexicano ha sido a la vez una de sus grandes tragedias. La decisión tomada en 1869 en el caso Miguel Vega que tuvo por efecto permitir el amparo judicial ha tenido por efecto sujetar a una capa procesal adicional a todo el litigio. En sí, ello no tenía por qué ser tan grave. Pero aunado a la forma, procesalitis, recursos intraprocesales, y tolerancia por el abuso del proceso, el resultado ha sido colesterol legal: un efecto embudo en el poder judicial que hace que cada asunto tarde mucho en resolverse. A veces lustros. A veces décadas. A veces más. 
Ante lo anterior, los particulares tienen una opción: cursar su problema vía arbitraje. Al hacerlo, escogen un mecanismo uniinstancial que evita los yo-yos procesales. Los amparos para efectos. La enorme cantidad de cosas que pueden hacerse para entorpecer un proceso. Y siendo que escogen a un especialista de su confianza, podrán la preocupación de control se reduce.

Pero si los actos de los árbitros se someten a control constitucional, lo anterior no se logra. Nunca habrá opción.

\subsection{Efecto en la causal de orden público}

Un laudo puede ser anulado o no ejecutado por ofender el orden público ${ }^{32}$. La concepción más refinada de la causal es "los principios más fundamentales de justicia y moralidad" de la jurisdicción en cuestión ${ }^{33}$. Aceptado que los derechos fundamentales son justamente eso, "fundamentales", ¿deben entenderse como comprendidos dentro del alcance de revisión conforme a la causal de orden público?

La respuesta es un "depende. No es unívoca. Existe sin embargo algo que esclarecer, matices que realizar y limites que identificar y tomar en cuenta a efecto de evitar malentendidos, errores o prestarse para tácticas deplorables.

Si por ejemplo un laudo propicia corrupción u ofende ius cogens dando efectos a situaciones universalmente deploradas ${ }^{34}$, la respuesta puede ser positiva: el laudo debe ser anulado. Sin embargo, si lo que se hace valer es violaciones procesales o incorrecta aplicación de derecho sustantivo considerado "importante" 35 , la respuesta debe ser negativa. Esto último puede ser difícil de aceptar e invitar problemas. Difícil de aceptar pues la no revisión de decisiones que versen sobre temas localmente sensibles (verbi gratia, normas imperativas) es la postura correcta mas no evidente de la interrogante - y una que ha probado ser de difícil aceptación para algunos ${ }^{36}$. Invitar problemas pues seguramente será usado como forma de cuestionar el fondo del laudo, comprometiendo su finalidad.

32. Artículo V(2)(b) de la Convención sobre el Reconocimiento y Ejecución de Sentencias Arbitrales Extranjeras de 1958 (“Convención de Nueva York").

33. Para abundar, véase ORden Público EN MÉXICO: DEL IMPRESIONISMO AL PUNTILLISMO JURÍdiCo (Boletín del Centro de Arbitraje de la Industria de la Construcción, noviembre 2012, www.caic.com.mx).

34. Por ejemplo, corrupción, esclavitud o piratería.

35. Por ejemplo, normas de aplicación inmediata.

36. Para entender por qué, véase LO LúdICO DEL ORDEN PÚBLICO, Revista de Investigaciones Jurídicas de la Escuela Libre de Derecho, México, 2014. (visible en www.gdca.com.mx) 
Para deslindar lo que debe quedar amparado de lo que no, propiciando que se eviten errores o se preste para tácticas dilatorias, propongo los siguientes principios:

1. En principio, el orden público no justifica analizar el fondo del laudo, incluyendo si el laudo acata derechos fundamentales;

2. Una violación a un derecho fundamental puede justificar anular o no ejecutar un laudo por actualización de la causal de orden público, pero no por que verse sobre un derecho fundamental, sino por que trastoca un principio elemental de justicia o moralidad. Esto merece profundización.

"Orden público" y "derechos fundamentales" son instituciones jurídicas diversas. Pueden haber comunes denominadores, pero también puede no haberlos. Se trata de dos recipientes conceptuales distintos que se traslapan en una serie de casos, pero que no admiten equiparación. Y este es el gran peligro de este tema: que un juzgador utilice la noción de "derecho fundamental" como atajo analítico para actualizar la noción "orden público". Hacerlo sería un yerro.

3. Como regla, el orden público procesal queda amparado por la carta magna del arbitraje ${ }^{37}$, y debe ser recurrido no por la causal de orden público ${ }^{38}$ sino por la causal consistente en que una parte "no ha podido hacer valer sus medios de defensa" 39 .

\section{La visión defendida merece ser seguida}

Deseo concluir con una explicación y una aclaración.

\subsection{Explicación}

Debemos aprender la gran lección que los economistas nos han dicho (yo diría, ad nauseam) y que muchos abogados seguimos sin escuchar:

37. Artículo 18 de la Ley Modelo de la UNCITRAL sobre arbitraje comercial internacional. Artículo 1434 del Código de Comercio de México.

38. Artículo V(2)(b) de la Convención de Nueva York.

39. Artículo $\mathrm{V}(1)(\mathrm{b})$ in fine de la Convención de Nueva York. 
para servir de cimiento para el progreso, el Derecho debe lograr dos cosas: i) Proveer reglas claras que sean ii) enérgicamente aplicadas.

La aplicación del constitucionalismo a las relaciones horizontales y su extensión a procesos arbitrales va en sentido contrario ${ }^{40}$. Resta claridad al derecho aplicable, y reduce la eficacia de su aplicación. El primero ocurre pues se sujeta a un análisis de ponderación la aplicación del derecho civil (incluyendo mercantil). Se exige un análisis constitucional sobre las normas civiles. Y siendo que el Derecho Constitucional está compuesto por valores, principios, su aplicación reside en lo que Robert Alexy llama "mandatos de optimización" 41 : el principio debe lograrse de la mayor manera posible, tomando en cuenta las circunstancias del caso particular. Ello es un ejercicio no solo diverso, sino incompatible, con el tipo de norma utilizada por el derecho civil: la regla ${ }^{42}$. Como resultado, ello querrá decir que, cuando uno firma un contrato, sus palabras estarán borrosas. El que signifique lo que dicen estará sujeto a lo que considere el juzgador competente que es acorde a los principios constitucionales caso por caso. Resultado: falta de claridad. El significado de la letra de un contrato dependerá del subjetivismo del juzgador que la aplique.

Respecto al segundo punto, el derecho aplicable distará de ser enérgicamente aplicado por el simple hecho que estará sujeto a una capa adicional de revisión. Por encima del régimen civil (incluyendo comercial) aplicable estará el derecho procesal constitucional. Lo que solía ser un par de recursos, ahora se convertirá en una multiplicidad de recursos. Y dadas las características de los recursos del derecho procesal constitucional que he descrito en la sección III.A(2) anterior), el resultado bien puede ser (y ya ha sido en algunos casos $\mathrm{y}$ en algunas jurisdicciones) que la solución a un problema se arroja a años después; a veces lustros; a veces más.

40. Tema que no abordo. Para abundar, se recomienda el ensayo de D. GArcía BARragán, El Arbitro Privado no es Autoridad para Efectos de la Ley de Amparo: EnTENdiendo la Lógica Detrás de la TeOría del DritTwirkung Der Grundrechte, El Foro, Vigésima Época, Tomo XXVI, número 2, Segundo Semestre 2013, México, D.F., p. 1. Mi postura puede consultarse en Costo Social del GARANTISMo, ob. cit., y GARANTiSmo y Arbitraje: Un FAlso Dilema, en Retos y Perspectivas del Derecho Mexicano del Siglo XXI, ¿Cómo debe evolucionar?, Colección Foro de la Barra Mexicana, Colegio de Abogados, A.C., Ed.Themis, México, D.F., 2012, p.1089; y GARANTISMO Y Arbitraje: Un FAlso Dilema POSt SCRIPTUM, (visible en www.gdca.com.mx/publicaciones).

41. R. Alexy, A Theory of Constitutional Rights, Oxford, 2010.

42. Mientras que las normas constitucionales sobre derechos fundamentales se conforman por principios, las normas civiles se componen de reglas. Se trata de técnicas jurídicas diversas. Usar el método analítico de uno para aplicar el otro es erróneo y estropea su efectividad. 
Como puede verse, la aplicación horizontal de los derechos fundamentales puede tener efectos serios en la utilidad del Derecho como instrumento de desarrollo. E irónicamente ello merma otro derecho fundamental: el de seguridad y certeza jurídica. Curiosamente, es un caso de utilización de palabras bonitas que tienen resultados feos. Lo cual despierta una ironía: permite utilizar el recurso libertario por excelencia (el juicio de amparo) para mermar derechos fundamentales (libertad y seguridad jurídica).

\subsection{Aclaración}

No faltará el lector especializado en derecho procesal constitucional que sienta que estoy cuestionando su área de especialización. Sobre ello, deseo dejar clara mi postura. En mi opinión:

1. Los desarrollos recientes sobre dicha disciplina son, en mi opinión, algunos de los más técnicamente estimulantes e idealmente emocionantes de toda la disciplina del Derecho (me refiero al control de convecionalidad, el contro difuso, y la fuerza que empieza a cobrar el control de convencionalidad difuso, tanto vertical como horizontal como paralelo) $)^{43} ; \mathrm{y}$

2. El derecho procesal constitucional tiene una importante labor que cumplir.

Si tuviera una varita mágica y pudiera reestructurar sistemas jurídicos, haría de los procesos constitucionales herramientas mucho más protagónicas en nuestras sociedades ${ }^{44}$. El motivo: me siento estimulado, persuadido y entusiasmado por el neo constitucionalismo. Por la importancia del Derecho Procesal Constitucional.

43. Ver al respecto, E. Ferrer Macgregor, Panorámica del Derecho Procesal ConstitucioNAL Y CONVENCIONAL, Ed. Marcial Pons, UNAM, 2014, pp. 753-754.

44. Dado el foro, no resisto la tentación de hacer alusión al golpe de Estado que el Tribunal Constitucional de Guatemala paró en 1993 con Jorge Serrano Elías. Pero no es el único ejemplo positivo. La Corte Constitucional de Colombia ha efectuado resoluciones inspiradoras (como la orden de mandar poner drenajes en barrios marginados y la impartición de justicia en comunidades indígenas marginadas), como también lo ha hecho el Tribunal Constitucional de Brasil (ordenando la entrega de medicamentos esenciales a personas sin recursos económicos) y la sala constitucional de Costa Rica. (Ver M. CARBONELL, EL Neoconstitucionalismo: SIgNificado y Niveles de ANÁLISIS, en El NANON NeOCoNSTITUCIONAL, Universidad del Externado de Colombia, Serie Intermedia de Teoría Jurídica y Filosofía del Derecho número 8, Bogotá, Colombia, 2010, pp. 163164.). 
Pero no dejo de ver los problemas que se detonan por su mal uso.

Mucho bien nos haría a los abogados escuchar y aplicar la sugerencia (más bien advertencia) que hacía el titán intelectual Rudiger DoRNBUSCH respecto de los instrumentos de la macroeconomía. Dornbusch solía advertir que para cada patología macroeconómica debe usarse una, y solo una, herramienta. El origen de muchos males de muchos países en el manejo de sus economías residía en utilizar una medicina para remediar varios males. Lo mismo pasa con el derecho procesal constitucional y desear poner bajo su lupa a los procesos arbitrales. Los juicios constitucionales son ideales para ciertos temas, para un género claro de problemas sociales. Usarlos para abordar otro tipo de males tiene por efecto propiciar otros problemas. En nuestro caso, se entorpecen los procesos arbitrales. Pero además, se diluyen los procesos constitucionales.

\subsection{Controlemos menos para tutelar más}

No me cansaré de decirlo: el juicio de amparo no debe ser una escopeta, debe ser un rayo láser. Irónicamente, debemos usarlo menos, para tutelar más. El juicio de amparo debe abarcar menos actos reclamados, para evitar diluirse. Es una cuestión no sólo de justicia, sino política pública. Los recursos públicos siempre son escasos. Ante ello, debemos encausarlos frugalmente; donde más se necesitan. Donde más impacto tienen. Llevado a nuestro tema, el punto sugiere la necesidad de zanjar la aplicación de los procesos constitucionales donde son más aptos. Donde más tutelan. Ello incluye no hacerlo aplicable a relaciones de coordinación ${ }^{45}$, en especial arbitraje. Después de todo, se trata de relaciones horizontales donde el leitmotif de los procesos constitucionales (poder público) no está presente, que es hecho aplicable voluntariamente por las partes, y que el núcleo de su decisión consiste en finalidad y uni-instancialidad.

\section{Conclusión}

Concluyo respondiendo la pregunta contenida en el título de mi ponencia: ¿son los procesos constitucionales y arbitrales agua y aceite? Respuesta:

45. Me refiero a la aplicación horizontal de los derechos humanos. 
"!Síj" Se trata de herramientas jurídicas que buscan cosas distintas. No deben mezclarse. Estando juntas en el mismo recipiente (sistema jurídico) cada una debe encontrar su espacio y ceñirse al mismo. No lograrlo tiene por resultado entorpecer - $j a$ ambas! 